\title{
The Effect of Self-Management Training Using CD on the Quality of Life in Patients with Chronic Heart Failure
}

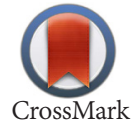

Tahereh Najafi Ghezeljeh ${ }^{1}$, Alireza Abbasi ${ }^{2 *}$, Mansoureh Ashghali Farahani ${ }^{2}$, Nasim Naderi ${ }^{3}$

1. Department of Intensive Care Nursing and Cardiovascular Perfusion Technology, Faculty of Nursing \& Midwifery, Iran University of Medical Sciences, Tehran, Iran.

2. Department of Medical-Surgical Nursing, Faculty of Nursing \& Midwifery, Iran University of Medical Sciences, Tehran, Iran

3. Rajaie Cardiovascular Medical and Research Center, Iran University of Medical Sciences, Tehran, Iran.

diftation: Najafi Ghezeljeh, T, Abbasi, AR, Ashghali Farahani, M \& Naderi, N 2016, 'The effect of self-management training using CD on the quality of life in patients with chronic heart failure', Journal of Client-Centered Nursing Care, vol. 2, no. 1, pp. 53-62. https://doi.org/10.32598/jccnc.2.1.53

: https://doi.org/10.32598/jccnc.2.1.53

Article info:

Received: 06 Aug. 2015

Accepted: 02 Nov. 2015
Keywords:

Chronic heart failure, Compact disc, Quality of life, Self-management training

\begin{abstract}
A B S T RA C T
Background: Chronic heart failure (CHF) can have negative effects on the quality of life (QoL). Self-management education is one of the approaches that can be adopted to increase the QoL of these patients. This study aimed to determine the effect of self-management training using compact disc $(\mathrm{CD})$ on the QoL in patients with $\mathrm{CHF}$.
\end{abstract}

Methods: This study was a non-randomized controlled clinical trial which was conducted on 74 patients with CHF hospitalized in Shahid Rajaie Cardiovascular medical and research center in 2015. Research samples were selected with convenience sampling method and randomly assigned to intervention (training with $\mathrm{CD}$ ) and control (conventional training) groups. To collect data, Iranian questionnaire to assess QoL in patients with heart failure (IHF-QoL) was completed in both groups before and 3 months after the intervention. Data analysis was done using statistical tests of the Independent $t$ test and paired t-test using SPSS version 21.

Results: According to the findings, there was no significant difference between two groups before the intervention with regard to QoL scores $(\mathrm{P}=0.58)$. Statistical tests showed that 3 months after the intervention, self-management education promoted QoL subscales including psychological status $(\mathrm{t}=-2.578, \mathrm{P}=0.012)$, self-care $(\mathrm{t}=-3.633, \mathrm{P}=0.001)$, as well as total $\mathrm{QoL}(\mathrm{t}=-2.01, \mathrm{P}=0.048)$ in patients in the intervention group as compared with the control group. Also in $\mathrm{CD}$ method group, themean scores of total QOL and its subscales before the intervention were significantly different from that mean scores 3 months after the intervention., i.e. their total QOL and its all subscales improved after intervention. $(\mathrm{P}<0.0001)$.

Conclusion: As self-management training with $\mathrm{CD}$ can improve QoL in patients with CHF compared with conventional training method, it is suggested that this training method be considered as a part of patients' self-management education by nurses with the aim of improving QoL.

\footnotetext{
* Corresponding Author:

Alireza Abbasi, MSc.

Address: Department of Medical-Surgical Nursing, School of Nursing \& Miwifery, Iran University of Medical Sciences, Tehran, Iran.

Tel: +98 (937) 5482857

E-mail:abbasi.isf@gmail.com
} 


\section{Background}

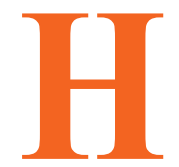

eart failure is a complex clinical syndrome that may be due to any disturbance in structure or function of the heart. Chronic heart failure (CHF) is the inability of the heart to meet the body's metabolic needs (Tissot et al. 2014). Patients with CHF have low quality of life (QoL) due to the multiple physical and mental disorders (Heidarzadeh et al. 2012). CHF has impact on all dimensions of life and can reduce QoL in every aspect. Thus, it is very important that the patient can manage these problems him/ herself (Smeulders et al. 2010; Heo et al. 2009).

Self-management is one of the interventions that can be used in chronic diseases, including CHF to improve QoL and reduce symptoms and hospitalizations. Self-management comprises measures taken with the aim of raising patient's awareness to promote his or her participation in chronic disease management, in particular monitoring of symptoms, and changing in health behaviors (Jonkman et al. 2014). In self-management, person is actively responsible for treatment and management of the daily symptoms and has a key role with respect to newly developed signs, performing interventions, disease management, and making informed decisions. Generally, the responsibility of the people increase in the face of public health.

Efficient self-management boosts individual's abilities and reactions which persuades patients in respect of longterm observance of the principles taught, promotion of individual participation, and reducing hospitalization of cardiovascular patients. Studies indicate that intervention-based self-management can enhance self-care and QoL (Baljani et al. 2012; Rezasefat et al. 2014; Tung et al. 2013).

By optimizing self-management behaviors in patients, nurses can help them in optimal control of symptoms. They promote the abilities of patients and encourage them to do what has learned (Hoffman 2013). Self-management behaviors must be presented to patients by nurses using appropriate teaching methods. Training can be provided in different ways in which lecture is the most common method and by using good content and lecturer, we can obtain positive, reasonable, and appropriate outcomes from this method.

There are many obstacles to develop self-management in patients, but new self-management educational programs, including the use of $\mathrm{CD}$ have the potential to overcome these obstacles and have a useful role to change patients' behaviors and decisions. Actually, such programs allow patients to meet their educational needs without being present in treatment centers, and reduce the cost of individual treat- ments, and finally improve self-management behaviors in patients (Dorn et al. 2014). Aghvami et al. (2015) study showed that not only the content of education was effective in improving QoL, but the manner of its presentation had important role in its results, so that teaching via $\mathrm{CD}$ was more effective on QoL in old 8-12 years children with asthma, compared with group educational method. Also Speck et al. (2016) showed that e-learning for 6 weeks can improve asthma control and enhance the QoL in patients with uncontrolled asthma. This study was conducted to determine the effects of self-management training program with CD on the QoL of the patients with CHF.

\section{Materials \& Methods}

This research was a part of a non-randomized controlled clinical trial. It was conducted on patients with $\mathrm{CHF}$ admitted to Rajaie Cardiovascular medical and research center, Tehran, Iran in 2015.

\section{Study patients}

After the permission of the Vice Chancellor for Research and Ethics Committee of Iran University of Medical Sciences (107/105/D/94) as well as authorities of Shahid Rajaie Cardiovascular medical and research center, the researcher referred to the research setting and relevant wards to select patients with $\mathrm{CHF}$ who met the inclusion criteria. After explaining the study purpose to the patients and their agreement to participate in the study, they signed written informed consent forms. Patients were assured regarding the confidentiality of their information, their freedom to decline cooperation and exiting from the study without making any problem in their treatment and care process.

The subjects were selected by convenience sampling method. Then, they were assigned in the intervention (CD method) and control groups by simple randomization. The name of groups (CD and control) was written on cards and were placed in a sealed envelope. At the beginning of each week and before encountering with the patients, by taking an envelope from the box, the researcher specified that patients who would be enrolled in each group. Samples, then, were selected for that group. After ensuring the discharge of the sampled patients, recruitment to select the next group was done.

Inclusion criteria were as follows; confirmed diagnosis of heart failure by physician, not being in acute phase of the disease, no sensory-perceptual problems, ability to communicate and literacy, as well as ability to use computers by the patient or a family member in the intervention group. To determine the required sample 
size at $95 \%$ confidence interval, power of $80 \%$, and assuming that the effect of $\mathrm{CD}$ method of training on QoL in patients with CHF has statistically significant difference of at least $7(\mathrm{~d}=7)$ with the control group and deviation in QoL is 10 according to the study of Tung et al. (2013), study sample size was calculated by the following formula:

$$
n=\left(Z_{1-\alpha}+Z_{1-\beta}\right)^{2} \times 2 s^{2} / d^{2}
$$

Accordingly, each group had 32 subjects. With 25\% drop out rate in each group, the sample size was considered 40 (Total sample size $=80$ ). Due to unwillingness of some patients to continue participation in the study, 6 people dropped out. Thus, 38 and 36 patients in the intervention group and control group, respectively were finally studied.

\section{Data collection}

In the current study, two questionnaires were used:

1) A demographic form: This questionnaire included questions about age, gender, educational degree, marital status, history of underlying disease, BMI, heart ejection fraction, duration of disease, the severity of disease due to heart failure, history of the disease family, number of children, income status, and medicines taken. This form was completed before the intervention by checking patient's file or asking the patients.

2) Iranian questionnaire to assess $\mathrm{QoL}$ in patients with heart failure (IHF-QoL): The questionnaire was developed by Naderi et al. (2012) and comprised 16 questions that examined physical symptoms such as shortness of breath, fatigue, peripheral edema, sleep disorder; psychiatric symptoms such as depression and anxiety; patient's social, physical, and sexual activity, as well as work, and emotions. Questions 1, 2, 3, 4, and 6 investigate symptoms and their severity, question 7 which has 4 parts investigates the patient's physical limitations, questions 8 , 10,12 , and 13 investigate social interference, questions 5,9 , and 11 investigate psychiatric conditions, questions 14 and 15 investigate the knowledge and self-efficacy and question 16 investigates life satisfaction of patients. The questions are scored according to Likert-type scale in which the larger the number, the better would be the patient's condition. Summing the total score of questions results in the total QoL score in which scores ranges from 15 to 63. Lower scores indicate poor QoL and higher total scores show better QoL. The Cronbach's $\alpha$ coefficient for IHF-QoL is 0.922 . And correlation coefficient tests were reported to be significant before and 3 months after the intervention (from 0.708 to 0.883 ; all $\mathrm{P}$-values $<0.001$ ) which was indicative of reliability of the questionnaire (Naderi et al. 2012). In this study, the Cronbach's $\alpha$ was 0.89 which indicated internal consistency of the tool.

Demographic questionnaire and IHF-QoL questionnaire were completed by subjects (CD method and control groups) before implementing the educational program. Also 3 months after the study, subjects (of both groups) were asked to attend the hospital to control the treatment process and complete the IHF-QoL.

\section{Intervention}

In the intervention group, including the patients and their family member were taught how to use the $\mathrm{CD}$ in one session for 20-15 minutes. They were asked to use the CD at home after discharge with the help of their families in the 3 months period. Educational content of $\mathrm{CD}$ included anatomy and physiology of the heart, introducing CHF, risk factors, symptoms, managing the symptoms of the disease, diagnostic solutions, diet, proper exercise, medication and side effects, blood pressure control method, and the calculation of body mass index.

These topics were stored in the $\mathrm{CD}$ as PowerPoint slides, training videos with subtitles in Farsi, related photos, and the full text of the training manual. Included in the $\mathrm{CD}$ were also applications necessary to run video, photos, PowerPoint, and the text. Patients in the intervention group were called by phone for 2-5 minutes in 1,2 , and 3 months after discharge. These conversations aimed at reviewing and emphasizing their use of the $C D$. Control group only received routine training. After collecting the information, content and educational CDs were delivered to patients in the control group, too.

\section{Data analysis}

To analyze the data, descriptive and inferential statistics including paired t-test for within-groups comparison, the Independent $\mathrm{t}$-test for between-groups comparison, the Chi-squared, and Fisher's exact test to compare qualitative variables between two groups, were used. All analyses were done by SPSS version 21. Significance level was also considered to be less than 0.05 .

\section{Results}

This study was conducted with the aim of investigating the effect of self-management training using $\mathrm{CD}$ on the QoL of patients with CHF. The demographic characteristics of the subjects suggested that the most frequently observed age group in the control and CD method groups 
Table 1. Demographic characteristics of the patients with $\mathrm{CHF}$ in the control and intervention groups.

\begin{tabular}{|c|c|c|c|c|}
\hline \multicolumn{2}{|c|}{ Variable } & $\begin{array}{c}\begin{array}{c}\text { Control group } \\
(n=38)\end{array} \\
\text { Mean } \pm \text { SD or \% (No.) }\end{array}$ & $\begin{array}{l}\text { Intervention group ( } n=36 \text { ) } \\
\text { Mean } \pm \text { SD or \% (No.) }\end{array}$ & P-value \\
\hline \multicolumn{2}{|c|}{ Age, y } & $51.60(15.29)$ & 44.05(13.16) & 0.026 \\
\hline \multirow{2}{*}{ Gender } & Male & $50.00(19)$ & $47.20(17)$ & \multirow{2}{*}{0.81} \\
\hline & Female & $50.00(19)$ & $52.80(19)$ & \\
\hline \multirow{3}{*}{ Marital status } & Single & $10.50(4)$ & $13.50(5)$ & \multirow{3}{*}{0.89} \\
\hline & Married & $84.20(32)$ & $80.61(29)$ & \\
\hline & Widow & $5.20(2)$ & $5.62(2)$ & \\
\hline \multirow{3}{*}{ Income } & Sufficient & $42.10(16)$ & $44.40(16)$ & \multirow{3}{*}{0.03} \\
\hline & Somewhat sufficient & $26.30(10)$ & $5.60(2)$ & \\
\hline & Not sufficient & $31.60(12)$ & $50.00(18)$ & \\
\hline \multirow{6}{*}{ Job } & Unemployed & $10.50(4)$ & $13.90(5)$ & \multirow{6}{*}{0.85} \\
\hline & Housewife & $36.10(13)$ & $39.50(15)$ & \\
\hline & Employee & $10.50(4)$ & $16.70(6)$ & \\
\hline & Self-employment & $21.11(8)$ & $11.10(4)$ & \\
\hline & Retired & $5.33(2)$ & $8.30(3)$ & \\
\hline & Others & $13.20(5)$ & $13.91(5)$ & \\
\hline \multirow{3}{*}{ Smoking } & Yes & $7.90(3)$ & $13.91(5)$ & \multirow{3}{*}{0.29} \\
\hline & No & $71.10(27)$ & $77.82(28)$ & \\
\hline & Quit smoking & $21.10(8)$ & $8.33(3)$ & \\
\hline \multirow{2}{*}{ Exercise } & Yes & $52.63(20)$ & $50.00(18)$ & \multirow{2}{*}{0.80} \\
\hline & No & 47.42(18) & $50.00(18)$ & \\
\hline \multirow{2}{*}{$\begin{array}{l}\text { Family history of } \\
\text { the disease }\end{array}$} & Yes & $50.00(19)$ & $33.30(12)$ & \multirow{2}{*}{0.14} \\
\hline & No & $50.00(19)$ & $66.75(24)$ & \\
\hline \multirow{4}{*}{ Education } & Elementary & $10.50(4)$ & $8.36(3)$ & \multirow{4}{*}{0.19} \\
\hline & Under diploma & $47.41(18)$ & $25.00(9)$ & \\
\hline & Diploma & $26.32(10)$ & 28.90(14) & \\
\hline & Higher education & $15.80(6)$ & $27.81(10)$ & \\
\hline \multirow{4}{*}{ Heart failure stage } & 1 & $00.00(0)$ & $00.00(0)$ & \multirow{4}{*}{0.33} \\
\hline & II & $55.29(21)$ & $50.00(18)$ & \\
\hline & III & $34.20(13)$ & $47.20(17)$ & \\
\hline & IV & $10.50(4)$ & $2.81(1)$ & \\
\hline \multirow{2}{*}{ Cause } & Ischemic & $52.61(20)$ & $33.30(12)$ & \multirow{2}{*}{$P=0.09$} \\
\hline & Non-ischemic & $47.40(18)$ & $66.73(24)$ & \\
\hline \multicolumn{2}{|c|}{ Ejection fraction, \% } & $30.92(8.96)$ & 31.47(8.07) & $P=0.78$ \\
\hline \multicolumn{2}{|c|}{$\mathrm{BMI}, \mathrm{kg} / \mathrm{m}^{2}$} & $24.30(5.32)$ & 23.86(6.29) & 0.04 \\
\hline
\end{tabular}


was 40-49 years and the statistical results showed that two groups were not matched in terms of age. The results showed that proportion of male to female patients in the control group was 1:1 but the number of males was higher in the intervention group $(n=19)$. In both groups, most of the subjects were married and housewives, also the majority did not smoke cigarette. With regard to educational degree, most individuals in the control group were under diploma (47.4\%) and in the CD method group, the highest frequency belonged to diploma holders (28.9\%). Frequency distribution and percentage of income in patients showed that the most frequent option in the control group was "sufficient" (42.1\%) and in the CD method group was "not sufficient" (50\%). In this respect, two groups were

Table 2. Comparison of QoL scores in patients with CHF in control and CD method groups before and 3 months after selfmanagement training.

\begin{tabular}{|c|c|c|c|c|}
\hline Groups & & CD Method $(n=36)$ & Control $(n=38)$ & \multirow{2}{*}{$\begin{array}{l}\text { Independent t-test } \\
\text { results }\end{array}$} \\
\hline \multicolumn{2}{|l|}{ Variables } & Mean(SD) & Mean(SD) & \\
\hline \multirow{3}{*}{$\begin{array}{l}\text { Symptoms and } \\
\text { their severity }\end{array}$} & $\begin{array}{l}\text { Before the inter- } \\
\text { vention }\end{array}$ & $11.50(3.29)$ & $10.28(3.47)$ & $\mathrm{t}=1.00, \mathrm{P}=0.320$ \\
\hline & $\begin{array}{c}\text { After the interven- } \\
\text { tion }\end{array}$ & $13.75(2.93)$ & $12.78(3.32)$ & $t=-1.31, P=0.19$ \\
\hline & $\begin{array}{l}\text { Paired t-test } \\
\text { results }\end{array}$ & $t=7.2, P<0.001$ & $t=-1.4, P=0.14$ & \\
\hline \multirow{3}{*}{$\begin{array}{c}\text { Physical } \\
\text { limitations }\end{array}$} & $\begin{array}{l}\text { Before the inter- } \\
\text { vention }\end{array}$ & $8.97(2.50)$ & $9.34(2.26)$ & $t=0.66, P=0.507$ \\
\hline & $\begin{array}{c}\text { After the interven- } \\
\text { tion }\end{array}$ & $9.80(2.32)$ & $9.63(2.04)$ & $t=0.34, P=0.73$ \\
\hline & $\begin{array}{l}\text { Paired t-test } \\
\text { results }\end{array}$ & $t=-4.3, P<0.001$ & $\mathrm{t}=-1.2, \mathrm{P}=0.214$ & \\
\hline \multirow{3}{*}{$\begin{array}{c}\text { Social } \\
\text { interference }\end{array}$} & $\begin{array}{l}\text { Before the inter- } \\
\text { vention }\end{array}$ & $9.44(1.91)$ & $9.42(1.42)$ & $t=-0.60, P=0.953$ \\
\hline & $\begin{array}{c}\text { After the interven- } \\
\text { tion }\end{array}$ & $10.27(1.50)$ & $9.86(1.57)$ & $\mathrm{t}=-1.41, \mathrm{P}=0.25$ \\
\hline & $\begin{array}{l}\text { Paired t-test } \\
\text { results }\end{array}$ & $t=-5, P<0.001$ & $\mathrm{t}=-2.8, \mathrm{P}=0.008$ & \\
\hline \multirow{3}{*}{ Psychological status } & $\begin{array}{l}\text { Before the inter- } \\
\text { vention }\end{array}$ & $6.33(1.56)$ & $6.10(1.55)$ & $t=-0.62, P=0.532$ \\
\hline & $\begin{array}{c}\text { After the interven- } \\
\text { tion }\end{array}$ & $7.41(1.38)$ & $6.65(7.21)$ & $t=-2.57, P=0.012$ \\
\hline & $\begin{array}{l}\text { Paired t-test } \\
\text { results }\end{array}$ & $t=-4.3, P<0.001$ & $t=-2.6, P=0.012$ & \\
\hline \multirow{3}{*}{ Self-efficacy and knowledge } & $\begin{array}{l}\text { Before the inter- } \\
\text { vention }\end{array}$ & $3.38(1.37)$ & $3.44(1.26)$ & $t=-0.67, P=0.850$ \\
\hline & $\begin{array}{c}\text { After the interven- } \\
\text { tion }\end{array}$ & $4.16(0.81)$ & $3.39(1.00)$ & $t=-3.63, P=0.001$ \\
\hline & $\begin{array}{l}\text { Paired t-test } \\
\text { results }\end{array}$ & $t=-4.1, P<0.001$ & $\mathrm{t}=0.29, \mathrm{P}=0.722$ & \\
\hline \multirow{3}{*}{ Life satisfaction } & $\begin{array}{l}\text { Before the inter- } \\
\text { vention }\end{array}$ & $2.50(0.73)$ & $3.00(0.56)$ & $t=-0.67, P=0.50$ \\
\hline & $\begin{array}{c}\text { After the interven- } \\
\text { tion }\end{array}$ & $2.66(0.47)$ & $2.18(0.69)$ & $t=-3.41, P=0.001$ \\
\hline & $\begin{array}{l}\text { Paired t-test } \\
\text { results }\end{array}$ & $t=-1.7, P=0.083$ & $t=1.7, P=0.088$ & \\
\hline \multirow{3}{*}{ Overall QoL } & $\begin{array}{l}\text { Before the inter- } \\
\text { vention }\end{array}$ & $39.63(7.76)$ & $40.60(7.38)$ & $\mathrm{t}=0.54, \mathrm{P}=0.58$ \\
\hline & $\begin{array}{c}\text { After the interven- } \\
\text { tion }\end{array}$ & $45.41(6.42)$ & $42.34(6.71)$ & $t=-2.01, P=0.048$ \\
\hline & $\begin{array}{l}\text { Paired t-test } \\
\text { results }\end{array}$ & $t=-1.80, P<0.001$ & $\mathrm{t}=-2.8, \mathrm{P}=0.007$ & \\
\hline
\end{tabular}


not homogeneous but the statistical results showed that this variable was not an confounding variable in the study. Both groups were homogenous in terms of having a regular exercise program and a history of the disease. In terms of the classification of heart failure according to the New York Heart Association (NYHA), patients in both groups were in class II of heart failure (Table 1). According to statistical tests, none of the demographic indicators were confounder in the test results.

The results of the Independent t-test showed that QoL and its subscales in patients with CHF had no significant difference in both groups before the intervention $(\mathrm{P}=0.58)$. However, after 3 months the control and intervention groups showed statistically significant differences $(\mathrm{P}=0.048)$ with regard to $\mathrm{QoL}$ scores. In other words, intervention improved the QoL of patients with CHF. Furthermore, after 3 months of intervention, QoL scores in subscales of psychological status $(\mathrm{P}=0.012)$, life satisfaction $(\mathrm{P}=0.001)$ and self-efficacy and knowledge $(\mathrm{P}=0.001)$ were significantly different between the intervention and control groups and have been improved. However, in other subscales no significant differences were observed between two groups (Table 2).

Based on the paired t-test results in the control group, QoL showed significant change after 3 months $(\mathrm{P}=0.007)$. Furthermore, the results of this test showed that in the intervention group there was a significant difference in terms of QoL 3 months after the intervention compared to the time before the intervention $(\mathrm{P}<0.001)$ and QoL has been improved. In reviewing various aspects of QoL in the intervention group, the statistical results of paired t-test showed that after 3 months, QoL scores of patients in all subscales (symptoms of heart failure, economic, social, psychological status, self-efficacy and knowledge, and daily activities of the individual) have been improved $(\mathrm{P}<0.001)$. With regard to different subscales of QoL in the control group, the statistical results of paired t-test showed that after 3 months of entering to the study, QoL scores of people in socio-economic $(\mathrm{P}=0.008)$ and psychological status $(\mathrm{P}=0.012)$ subscales significantly changed and QoL improved in these areas. However with regard to other subscales, no significant changes were observed in the control group before and 3 months after the start of the study (Table 2).

\section{Discussion}

Based on our findings, self-management education with CD method has improved QoL of patients with CHF compared with the control group. In line with the results of this study, Tung et al. (2013) showed that self-management training had a positive impact on QoL of patients with CHF compared with the control group. Likewise, Shu-Hui et al. (2014) conducted a study to investigate the effect of self-management training on QoL of patients with chronic obstructive pulmonary disease (COPD). They reported that self-management programs resulted in improvement of QoL through shortening the acute phase of the disease and its recurrence. Baljany et al. (2012) addressed the effect of self-management by increasing patients' awareness on the medicines adherence and changing lifestyle of patients with cardiovascular disorders.

However in a review study, out of 19 studies reviewed, in 5 studies, self-management training had no effect on QoL of patients with CHF. Nevertheless, the methodological limitations of the studies evaluated in this review could be the cause of insignificant effects of the intervention on QoL. Self-management interventions are part of a multifaceted CHF intervention program and patients' education is a key component of self-management, which its teaching is necessary to create awareness of the signs and symptoms, lifestyle changes, and adherence to treatment (Ditewig et al. 2010). In this regard, there are different methods of education with various effects on QoL. One can argue that compared to the conventional methods, like face-to-face training and giving educational pamphlets, using educational CDs could improve QoL education. Also according to the findings in CD method group, QoL in patients with CHF after 3 months of training have had a significant improvement, compared with their QoL before the training period.

Mean score of QoL in these patients was improved after the training. In line with this study, Strömberg et al. (2006) showed that computer-based training such as using educational CD compared with conventional methods could promote knowledge, change the behavior, and improve selfcare in patients with CHF. However, Dilles et al. (2011) in a study comparing the effects of two educational methods of using the educational $\mathrm{CD}$ and conventional method on self-care and knowledge of the patients with CHF showed that both methods can improve the level of knowledge and self-management of the hospitalized patients with $\mathrm{CHF}$ Nevertheless, there was no significant differences between 2 groups with regard to knowledge $(\mathrm{P}=0.65)$ and self-care $(\mathrm{P}=0.40)$, and it cannot be concluded that educational $\mathrm{CDs}$ can be used as an alternative to traditional training methods. Also in the current study, it was found that both conventional and $\mathrm{CD}$ methods improved the QoL compared with pre-intervention period; however, this improvement was higher in the intervention (CD method) group. 
Comparing two groups, 3 months after the intervention, revealed that, self-management education with $\mathrm{CD}$ improved QoL (compared with the control group) in these subscales: symptoms of heart failure, socio-economic and psychological status, daily activities, self-efficacy, and knowledge. However, these differences were statistically significant only in the areas of socio-economic status, selfefficacy, and knowledge.

Also with regard to within group comparison, the results showed that in the control group, an improvement was observed in the socio-economic status and consequently, in total QoL, 3 months after the study. However, this socioeconomic improvement was higher in the CD method group after 3 months of intervention. Similarly, another study reported that self-management education programs can play an effective role in the economic status of patients with COPD by reducing the cost of readmission and also the number of patients admitted to hospital (Bourbeau et al. 2006). The results also showed that 3 months after the intervention compared with the pre-intervention period, $\mathrm{QoL}$ improved in all aspects of QOL in the intervention group.

In another study, it was shown that limitations in physical activities, mental disorders such as anxiety, and lack of knowledge about the disease can negatively affect QoL of these patients and it was proposed that the patient education be done to alleviate these problems (Malhotra et al. 2016). Similar to our study which indicated the QoL improvement in the psychological aspect, McCorkle et al. (2011) reported that self-management training in patients with cancer could improve the management of the symptoms and reduce their anxiety and psychological problems in different courses of treatment and even after treatment, and consequently enhance patients' QoL. One of the problems in patients with heart failure is limitations in physical activity. With regard to the QoL aspect of individual's daily activities, the mean(SD) score in the control group (which has been provided with conventional self-management training) promoted significantly from 9.34(2.26) to 9.63(2.04). Likewise, in the intervention group, daily activities mean(SD) scores improved significantly from $8.97(2.50)$ to $9.80(2.3)$.

In line with these results, a study showed that life style of patients with CHF can be changed using different teaching methods and improving physical activity of these patients can prevent worsening of the disease and their restrictions (Dontje et al. 2014). In self-management teaching group using $\mathrm{CD}$, the mean(SD) score of self-efficacy and knowledge subscales improved from 3.38(1.37) to 4.16(0.81). Similarly, a study with the aim of comparing the computer-assisted training (using $\mathrm{CD}$, including contents such as videos, photos, etc.) and education using standard methods (giving brochures and face-to-face training) on patients with heart disease showed that the level of knowledge and self-care in patients with CHF improved with both methods, but there was no significant difference between the two methods in terms of impact on self-care and self-efficacy (Dilles et al. 2011). de Walt et al. (2006) also reported that patients with CHF who were taught with different educational methods performed more self-care control behavior over their daily weight compared to the patients in the control group. Also in their study, Strömberg et al. (2002) concluded that in CD method group, training with CD increased patients' knowledge, self-care, and self-efficacy compared with the control group.

Among the limitations of this study was impossibility of blinding because of the nature of the intervention. Other limitation was failure to use block randomization method in sample selection. Also the impact of the intervention was evaluated in a 3-month period which is not long enough. We recommend that future studies be conducted with the aim of investigating the effects of longterm self-management training with $\mathrm{CD}$ on these patients. To determine the most suitable training approach, we suggest that different methods of teaching and their effects on QoL and self-management behaviors of these patients be compared. In this study, in addition to giving educational $\mathrm{CD}$, telephone calls were made to be ensured of using $\mathrm{CD}$. This was not done in the control group. Although in these calls, we tried only to emphasize the use of the CD, a study should be conducted with three groups under the conventional training and telephone follow-ups to ensure implementation of training tips to obtain the net effect of education considering follow-ups.

In this research, the effect of self-management training with CD on the QoL of patients with CHF was investigated. Research results showed that self-management education using common methods (face-to-face education and providing an educational pamphlet at the time of discharge) and CD-based educational can increase QoL of patients with CHF. The results showed that education with $\mathrm{CD}$ in the intervention group has led to more improvement in QoL of patients with CHF, compared with the control group. Self-management education is an appropriate way to improve QoL in patients with CHF and these trainings enhance the skills of patients to manage disease on their own. One important finding of this study was the role of modern methods of training in further improvement of QoL in patients. It is recommended that caregivers, especially nurses use educational CDs along with common methods in training patients with CHF. Furthermore, we 
propose that a useful teaching method of self-management to patients with CHF should be included in nursing curriculum at health care centers and universities. By teaching with modern methods like CDs to nurses and nursing students, a step is taken towards promoting self-management and QoL in patients with CHF.

\section{Acknowledgments}

This article is extracted from the thesis of Nursing and Midwifery School of Iran University of Medical Sciences. Researchers thank staff and directors of the Nursing and Midwifery School of Iran University of Medical Sciences and Shahid Rajaee Hospital and all those who participated and cooperated in the study.

\section{Conflict of Interest}

The authors declared no conflict of interests.

\section{References}

Aghvamy, M, Mohammadzadeh, S, Gallalmanesh, M \& Zare, R 2011, '[Assessment the education compariment to two ways: groupe education and computer education on qol in the children 8-12 years suffering from asthma in the Valiasr Hospital of Zanjan (Persian)]'. Zanjan University of Medical Sciences Journal, vol. 19, no. 74, pp. 78-85.

Baljani, E, Rahimi, Zh, Heidari, Sh \& Azimpour, A 2012, '[The effect of self-management interventions on medication adherence and life style in cardiovascular patients (Persian)]'. Scientific Journal of Hamadan Nursing \& Midwifery Faculty, vol. 20, no. 3, pp. 58-68.

Bourbeau, J, Collet, JP, Schwartzman, K, Ducruet, T, Nault, D \& Bradley, C 2006, 'Economic benefits of self-management education in COPD', Chest, vol. 130, no. 6, pp. 1704-711. doi: 10.1378/ chest.130.6.1704

de Walt, DA, Pignone, M, Malone, R, Rawls, C, Kosnar, MC, George, G et al. 2004, 'Development and pilot testing of a disease management program for low literacy patients with heart failure', Patient education and counseling, vol. 55, no. 1, pp. 78-86. doi: 10.1016/j.pec.2003.06.002

Dickestein, K, Cohen-Solal, A, Filippatos, G, Mcmurray, JJ, Ponikowski, P, Poole-Wilson, PA et al. 2008, 'ESC guidelines for diagnosis and treatment of acute and $\mathrm{CHF}^{\prime}$, European Heart Journal, vol. 29 , no. 19, pp. 388-442.

Dilles, A, Heymans, V, Martin, S, Droogné, W, Denhaerynck, K \& de Geest, S 2011, 'Comparison of a computer assisted learning program to standard education tools in hospitalized heart failure patients', European Journal of Cardiovascular Nursing, vol. 10, no. 3, pp. 187-93. doi: 10.1016/j.ejcnurse.2010.07.001

Ditewig, JB, Blok, H, Havers, J \& van Veenendaal, H 2010, 'Effectiveness of self-management interventions on mortality, hospi- tal readmissions, CHF hospitalization rate and QoL in patients with CHF: a systematic review', Patient Education \& Counseling, vol. 78, no. 3, pp. 297-315. doi: 10.1016/j.pec.2010.01.016

Dontje, ML, van der Wal, MH, Stolk, RP, Brügemann, J, Jaarsma, T, Wijtvliet, PE et al. 2014, 'Daily physical activity in stable heart failure patients', Journal of Cardiovascular Nursing, vol. 29, no. 3, pp. 218-26. doi: 10.1097/JCN.0b013e318283ba14

Dorn, S, Palsson, O, Woldeghebriel, M, Fowler, B, Mccoy, R, Weinberger, M et al. 2014, 'Development and pilot testing of an integrated, web-based self-management program for irritable bowel syndrome (IBS)', Neurogastroenterology \& Motility, vol. 27, no. 1, pp. 128-34. doi: 10.1111/nmo.12487

Heidarzadeh, M, Hasani, P, Rahimzadeh, A, Ghahramanian, A Kolahdouzipour, J \& Yousef, I 2012, '[QoL and social support in congestive heart failure patients and healthy people (Persian)]', Holistic Nursing \& Midwifery Journal, vol. 23, no. 69, pp. 13-21.

Heo, S, Lennie, TA, Okoli, C \& Moser, DK 2009, 'Quality of life in patients with heart failure: ask the patients', Heart \& Lung: The Journal of Acute and Critical Care, vol. 38, no. 2, pp. 100-108. doi: doi: 10.1016/j.hrtlng.2008.04.002

Hoffman, AJ 2013, 'Enhancing self-efficacy for optimized patient outcomes through the theory of symptom self-management', Cancer Nursing, vol. 36, no. 1, pp. 16-26. doi: 10.1097/ NCC.0b013e31824a730a

Jonkman, NH, Westland, H, Trappenburg, JC, Groenwold, RH, Effing-Tijdhof, TW, Troosters, T et al. 2014, 'Towards tailoring of self-management for patients with CHF or chronic obstructive pulmonary disease: a protocol for an individual patient data meta-analysis', BMJ Open, vol. 4, no. 5, p. e005220. doi: 10.1136/ bmjopen-2014-005220

Malhotra, C, Wong, GC, Tan, BC, Ng, CS, Lee, NC, Lau, CS et al. 2016, 'Living with heart failure: Perspectives of patients from Singapore', Proceedings of Singapore Healthcare, vol. 25, no. 2, pp. 92-97. doi: $10.1177 / 2010105815624121$

McCorkle, R, Ercolano, E, Lazenby, M, Schulman-Green, D, Schilling, LS, Lorig, K et al. 2011, 'Self-management: Enabling and empowering patients living with cancer as a chronic illness', CA: A Cancer Journal for Clinicians, vol. 61, no. 1, pp. 50-62. doi: 10.3322/caac.20093

Mozaffarian, D, Benjamin, EJ, Go, AS, Grnett, DK, Blaha, MJ, Bushman, M et al. 2015, 'Heart disease and stroke statistics--2015 update: a report from the American Heart Association', Circulation, vol. 131, no. 4, pp. 299-322. doi: 10.1161/CIR.0000000000000152

Reihani, T, Pourghaznein, T, Ajam, M \& Hasanzadeh, F 2012, '[A comparative study of lecturing and providing booklet on nursing students' learning and satisfaction (Persian)]', Modern Care Journal, 2012, vol. 9, no. 4, pp. 285-91.

Rezasefat Balesbaneh, A, Mirhaghjou, N, Jafsri Asl, M, Kohmanaee, S, Kazemnejad Leili, E \& Monfared A 2014, '[Correlation between self-care and self-efficacy in adolescents with type 1 diabetes (Persian)]', Holistic Nursing and Midwifery Journal, vol 24, no. 2, pp. 18-24.

Smeulders, ES, van Haastregt, J, Ambergen, T, Uszko-Lencer, NH Janssen-Boyne, JJ \& Gorgels, AP et al. 2010, 'Nurse-led self-management group programme for patients with congestive heart failure: randomized controlled trial', Journal of Advanced Nursing, vol. 66, no. 7, pp. 1487-499. doi: 10.1111/j.1365-2648.2010.05318.x 
Sol, BG, van der Bijl, JJ, Banga, JD \& Visseren, FL 2005, 'Vascular risk management through nurse-led self-management programs', Journal of Vascular Nursing, vol. 23, no. 1, pp. 20-24. doi: 0.1016/j.jvn.2004.12.003

Speck, A, Hess, M \& Baptist, AP 2016, 'An electronic asthma selfmanagement intervention for young African American adults', Immunology in Practice, vol. 4, no. 1, pp. 89-95. doi: 10.1016/j. jaip.2015.08.007

Strömberg, A, Ahlén, H, Fridlund, B, Dahlström, U 2002, 'Interactive education on CD-ROM-a new tool in the education of heart failure patients', Patient Education \& Counseling, vol. 46, no. 1, pp. 75-81. PMID: 11804773

Strömberg, A, Dahlström, U \& Fridlund, B 2006, 'Computer-based education for patients with CHF: a randomised, controlled, multicentre trial of the effects on knowledge, compliance and QoL', Patient Education \& Counseling, vol. 64, no. 1, pp. 128-135. doi: 10.1016/j.pec.2005.12.007

Tissot, C, da Cruz, EM \& Miyamoto, SD 2014, 'Congestive heart failure', in E da Cruz, D ivy, J Jaggers (eds.), Pediatric and congenital cardiology, cardiac surgery and intensive care, Springer-Verlag, London. doi: 10.1007/978-1-4471-4619-3_229

Tung, HH, Lin, CY, Chen, KY, Chang, CJ, Lin, YP \& Chou, CH 2013, 'Self-management intervention to improve self-care and quality of life in heart failure patients', Congestive Heart Failure, vol. 19, no. 4, pp. 9-16. doi: 10.1111/chf.12014

Wilson, PM, Kendall, S \& Brooks, F 2006, 'Nurses' responses to expert patients: the rhetoric and reality of self-management in long-term conditions: a grounded theory study', International Journal of Nursing Studies, vol. 43, no. 7, pp. 803-818. doi: 803-18. 10.1016/j.ijnurstu.2005.10.011

Yu, S, Guo, A \& Zhang, X 2014, Effects of self-management education on QoL of patients with chronic obstructive pulmonary disease', International Journal of Nursing Sciences, vol. 1, no. 1, pp. 53-57. doi: 10.1016/j.ijnss.2014.02.014 
